\title{
El Impulso y la Preclusión Procesales
}

\author{
Por el Dr. RICARDO NUGENT I. CH.
}

El Profesor Alsina, refiriéndose al impulso procesal, manifiesta que "el proceso es un organismo sin vida propia que avanza junstamente en virtud de los actos de procedimiento. Esta fuerza externa que los mueve se llama impulso procesal, que vinculado con la institución de los términos los cuales ponen un límite en el tiempo a los actos procesales, y con el principio de la preclusión, que establece un orden sucesivo, hace posible el desenvolvimiento progresivo del proceso" (1). $\AA$ su turno Piero Calamandrei añade que impulso procesal "es la fuerza motriz que interviene en el curso del procedimiento para evitar que el mismo se estanque" (2). W. Kirch con otras palabras expresa el mismo concepto cuando dice cye el impulso procesal "es la actividad que es necesaria para poner en movimiento el procedimiento y conducirlo hacia su fin" (3).

De todos estos conceptos se desprende que el impulso procesal estíx formado por dos elementos fundamentales: los actos procesales que mantienen en movimiento el proceso, y los sujetos que hacen desarrollar esas actividades llamadas actos procesales. El impulso procesal es pues un mo. vimiento progresivo al que queda sujeto el proceso, desde que la deman. da se presenta al magistrado hasta el fin del procedimeinto.

Los sujetos del impulso procesal son las personas que actúan en el proceso, ora en interés propio, ora en razón del cargo que desempeñan, cra por obligación legal inevitable. Las partes actúan en el proceso en interés propio, el Juez por razón del cargo que desempeña, y los testigos, feritos $y$ en general los terceros por expreso mandato de la ley. Todos eilos son sujetos del impulso procesal porque colaboran a este movimiento progresivo merced al cual el proceso puede desenvolverse desde la demanda hasta la sentencia. Sin embargo conviene hacer una distinción tntre estos sujetos del impulso procesal y es la siguiente: las partes y el Juez son las personas que están más ligadas entre sí, por razones que no es necesario destacar, en cambio los terceros, ocupan dentro del proceso una posición que podríamos llamar tangencial, un tanto al margen si se quiere; por consiguiente hay que aceptar que, en sentido estricto; los verdaderos sujetos del impulso procesal son el Juez y las partes, ya que los actos realizados por ellos son los que impulsan verdaderamente el yroceso.

(1) Tratado Teórico Prácticò de Derecho Civil y Comercial, pág. 261 párrafo 19.

(2) Instituciones de Derecho Procesal Civil, pág. 283 párrafo 19 .

43) Elementos de Derecho Procesal Civil pág. 147 pámato 59. 
Para el notable procesalista uruguayo Eduardo J. Couture (4), las partes pueden efectuar actos que él denomina de obtención Y constitutivos. Entre los primeros consigna las peticiones formuladas al magistrado para que dicten una resolución; las afirmaciones sobre puntos de derecho o sobre hechos simplemente, que se dirigen al mismo Juez para que sea acogida la petición; pruebas o sea actos de las partes encaminados a acreditar el fundamento de sus afirmaciones. Entre los actos constitutivos se encuentran las declaraciones unilaterales de voluntad, como por ejemplo, la revocación de un mandato, el desistimiento; los convenios de carácter procesal para solucionar una litis, como la transacción; la conciliación; las farticipaciones de voluntad como la confesión judicial, el juramento decisorio, el allanamiento de la demanda.

Empero, en términos generales los actos procesales que realiza el Juez son los decretos, las providencias, los autos y las sentencias. Estos actos no siempre se ejecutan y se llevan adelante por iniciativa de las partes, puede haber casos en que esta iniciativa sea del resorte del juzgador, siguiendo el sistema inquisitivo del proceso. De esta distinción surgo la diferencia entre el impulso procesal de parte y el impulso procesal de oficio, a la que A.lsina ogrega otro término: el impulso procesal legal, que según él, se realiza cuando la ley impone en forma imperativa a las fartes el cumplimiento de determinados actos procesales, verbi gratia, el caso de los términos perentorios, en virtud de los cucles se pierde por preclusión el ejercicio de algún derecho. No participamos de la opinión del traiadista argentino, ya que no siendo la ley sujeto de derecho, no puede tampoco ser sujeto del impulso procesal. La Ley no puede actuar por sí sola, sino a través de un sujeto que puede ser como hemos visto o una de las partes o el Juez o los terceros. El impulso procesal puede ser a soliciiud de parte o de oficio, pero nunca legal. Ademós ya se ha establecido que el impulso procesal es privativo de los sujetos que intervienen en el proceso, y la ley no es un sujeto, sino una norma abstracia que requiere de las partes o del magistrado para poder materializarse en las soluciones concretas que la vida nos presenta.

Cuando una legislación procesal acepta como principio básico de su ordenamiento jurídico el sistema dispositivo, todas las actividades que hacen mover el proceso están libradas a la iniciativa de las partes, en consecuencia el impulso procesal depende exclusivamente de las partes que intervienen en el proceso, $\alpha$ tal punto que si ellas dejan de realizar los actos procesales que establece la ley, el proceso se paralizc, no avanza; esto puede acontecer cuando una de las partes pierde el interés en el pleito y a la otra le conviene esperar el plazo legal del abandono de la instancia, o también cuando las partes convienen en llegar a un acuerdo extrajudicial sobre el hecho materia de controversia.

El Profesor Calamandrei ha dicho muy bien "que el proceso es una relación dialéctica de actividades en que todo acto puede representar una reacción respecto de áquel que lo ha practicado y un estímulo respecto de

(4) Estudios de Derecho Procesal Civil, t. 1, pág. 60. 
aquel que debe seguirlo" (5). De tal manera que la parte cuando realiza un acto procesal determinado, está reaccionado ante un acto realizado por su contraparte y esta reacción sirve de estímulo y determina una nueva, $\mathrm{y}$ así sucesivamente hasta finalizar el proceso. Este raciocinio, perfecto desd? €l punto de vista teórico, sufre en la práctica algunas alteraciones, ya que puede suceder que una parte por ejemplo, no concurra a prestar confesión, a exhibir un documento o no absuelva un traslado, y en estos casos, no sería justo que el proceso se paralizara indefinidamente, porque un proceso no puede estar sujeto a la inércia o inactividad de los litigantes, por eso existe la institución de la rebeldía que permite el avance del proceso aún cuando una de las partes no realice los actos procesales indicados por la ley.

Existen legislaciones procesales como la austriaca, en las que los actos procesales son provocados por el Juzgador de "muto proprio", sin necesidad de que las partes tengan la iniciativa. Siguen pues el sistema inquisitivo y por consiguiente el impulso procesal es el denominado "de oficio", en contraposición al impulso procesal de parte. La intervención del Juez en esta hipótesis tiene dos objetivos: hacer que las partes realicen el acto y dictar las medidas conducentes a que el proceso no se paralice por la omisión anotada. En este sentido se dice con razón que el impulso procesal no requiere el concurso de las partes y aunque ellas no tengan el menor interés en la progresión del proceso, el Juez, haciendo uso de esa iniciativa que le confiere la ley, deja sentir su voluntad impulsando el proceso. Dentro del sistema inquisitivo el magistrado está facultado para ordenar pruebas sin que las partes se lo pidan, para declarar rebelde a quien no cortesta un traslado, y en fin para realizar todos los actos procesales que gaIcnticen el desarrollo del proceso.

Este sistema ha sido adoptado por el Código de Santa Fé (Art. 70\%), for el de Córdova (Art. 97\%) y por el Español para el Protectorado de MaIruecos (Art. 242\%).

Entre las dos disposiciones antagónicas que se han expuesto ha surgido un tercer sistema que se adapta más a la realidad, y vemos en la práctica que la mayoría de las legislaciones procesales toma parte del impulso procesal de parte y otra del impulso procesal de oficio, formándose así el denominado impulso procesal mixto. Este sistema es sin duda alguna el más apropiado a los fines del proceso.

En efecto, se ha objetado el impulso procesal de oficio diciendo que el Juez se toma atribuciones que corresponden exclusivamente a las partes, porque a ellas lo que les interesa es la justicia, de otra manera no se expiica que hayan comparecido ante las autoridades judiciales en demanda de sus pretensiones; y si las partes permiten que se estanque el proceso es $\alpha$ ellas a quienes perjudica esta paralización, sin que en nada se afecte €i interés social.

Contra estas alegaciones oponemos la autorizada opinión de Couture cuancio en la Exposición de Motivos de su Proyecto de Código de Procedimiento Civil dice que "si un ciudadano no puede despojor a otro de sus bienes en

(5) Op. cit. pág. 281 párrafo 29. 
presencia de la cutoridad sin que ésta lo reduzca a prisión, no se concibe en virtud de que razonamiento un Juez deba presenciar impasible como un litigante deshonesto, arruine, burle $\mathrm{y}$ defraude $\alpha$ un litigante honesto, sin poner en juego un mínimo de autoridad para evitar el despojo que se consuma ante él (6).

El Juez debe intervenir en el proceso, no en forma dictatorial claro está, sino con ese poder ordenador que le confiere la ley en su calidad de representante del Poder Público. Ya no puede admitirse el proceso como una relación exclusiva entre dos particulares, donde el Juez no es mas qua un simple espectador o árbitro deportivo que dará la victoria al vencedor. Se ha dicho con razón que un Juez sin interés en el litigio es como un médico $\sin$ interés en el enfermo.

Por otro lado, con el impulso procesal mixto se logra un equilibrio entre las facultades de las partes y los poderes del Juez, evitando los excesos de los litigantes y mitigando las arbitrariedades en que pudiera incurrir el Juzgador.

No es necesario hacer un análisis detallado de nuestro Código de Frocedimientos Civiles, para concluír que nuestra legislación está afiliada $a_{i}$ principio dispositivo del pröceso, y que por lo tanto el impulso procesal está librado a la iniciativa de las partes. No obstante del detenido examen que hemos realizado saltan a la vista varias disposiciones que prevalentemente pertenecen al sistema inquisitivo, contrastando con el sistema adoptado por el Código, por influencia tanto del Código de Enjuiciamientos Civiles que lo precedió, como por la Constitución del 60 y el Código Civil do 1852, promulgados en el apogeo del individualismo.

Efectivamente, la disposición que establece que no se dará curso ni efecto alguno a los escritos, mientras no se haga la designación de domicilio (Art. 114\%); la que obliga a las partes a acompañar bajo su firma copias de los escritos y documentos que presenten, sin cuyo requisito no serán odmitidos por el Escribano o Secretario de Corte (Art. 124\%); la que autoriza al Juez a dictar apremios de oficio con el objeto de conséguir el pago ae las multas destinadas a fondos de justicia (Art. 1979); la que faculta al Juez para repeler de oficio los incidentes que no tengan relación con el cibjeto principal del pleito (Art. 202\%); la que cutoriza al Juez a decretar de cficio la acumulación de procesos cuando se encuentre en el mismo Juzga. do; la que faculta al Juez para devolver las demandas que carezcan de los requisitos legales (Art. $307^{\circ}$ ); la que concede al magistrado el derecho de crdenar pruebas de oficio en cualquier estado de la causa (Art. 340\%); y en algunos otros casos más que sería innecesario destacar.

Desgraciadamente la influencia del sistema dispositivo y por lo tanto el predominio del impulso de parte, ha hecho que nuestros jueces no apliquen muchas veces estas disposiciones, pon considerar equivocadamente que el uso de estas facultades que les otorga la ley constituye una extralimitación de sus funciones.

De los preceptos citados ,apenas si podemos mencionar a las pruekas y los apremios de oficio, como de frecuente aplicación: las demás exis-

(6) pág. 92 p. 19. 
ten sólo en el Código de Procedimientos Civiles, pero no en la vida judicial, salvo rarísimas excepciones. Los abogados en ejercicio estamos frente a la diaria corruptela de los frecuentes incidentes que se suscitan porque una de las partes no presenta las copias simples correspondientes; 0 forque habiéndolas recibido niegan el hecho. $Y$ es obvio que estos incidentes terminarían definitivamente si se diera cumplimiento a la terminante disposición del Art. $124^{\circ}$ del Código de Procedimientos Civiles, glosado en párrafos anteriures. Igualmente no es raro que se admita alqunas deman. cias que no reunen las formalidades prescritas por el Art. $306^{\circ}$ y muchas veces se sustancia el procedimiento sin cumplirse con este requisito, siguiéndose como es natural, la nulidad de todo lo actuado. La misma crít:ra cabe hacer respecto de la falta de aplicación de los demás dispositivos que se han indicado, $y$ sobre todo a la inveterada costumbre de correr traslcdo de todas las peticiones maliciosas que hacen las partes en vez de repelerlas de oficio como lo manda el Art. 202 $2^{\circ}$ del Código de Procedimientos Civiles.

Todas estas razōnes nos llevan a la conclusión que el impulso procesal debe basarse en la coordinación entre las partes y el Juez, lo que evidentemente nos inclina $\alpha$ acherimos sin reservas al sistema que preconiza el impulso procesal mixto.

Pero la función jurisdiccional sería ilusoria si ese avance del proceso no se llevará adelante siguiendo un orden preestablecido; es necesario que el proceso se desarrolle por medio de etapas independientes que no obstante formen un todo orgánico. A la demanda siguen las excepciunes si son deducidas; resueltas éstas negativamente, la contestación, luege la apertura de la causa a prueba, los alegatos y la sentencia tratándose por supuesto del juicio ordinario, y en forma análoga sucede en los juicios especiales y sumarios. Todo esto determina que pasada una etapa, ya no se puede volver sobre la anterior, pues de admitir esta probabilidad el proceso seria un caos y los esfuerzos de las partes y del Juez por hacer civanzar el proceso, sería nulo, reinaría el desconcierto y el desorden en jerjuicio del normal desenvolvimiento del proceso y del interés de las partes. A este efecto de clausurarse la etapa anterior es lo que se ha dado en llamar la preclusión procesal.

El sistema contrario al de la preclusión procesal es el denominado for la doctrina "unidad de vista", es decir, que el proceso no se realiza por secciones o estadíos independientes que forman un solo todo; es posible alegar hechos nuevos, ofrecer y actuar pruebas de toda clase hasta que el Juez pida los autos para sentencia. Es el sistema clemán. Empero, la urgencia de llevar con orden los procesos ha hecho, como no podía dejar cie hacerse, que predomine el sistema de la preclusión procesal en la mayoría de las legislaciones.

Chiovenda ha definido la preclusión como una institución general que tiene frecuentes aplicaciones en el proceso y que consiste en la pérdida de una facultad procesal por haberse llegado a los límites fijados por la ley para el ejercicio de esta facultad en el juicio o en una fase de él.

En términos mós explícitos se refiere expresamente a la preclusión el Artículo 227\% del Cóciigo de Procedimientos Civiles Mejicano: "consiste la 
freclusión en la pérdida del derecho que compete a las partes en juicio Fara realizar determinados actos procesales después que se han ejercitc. do otros actos o ha transcurrido cierto término legal, y tiene por objeto dar precisión y seguridad al procedimiento y atribuir firmeza a las resoluciones judiciales, que sin producir excepción de cosa juzgada, tiene efectos que han de ser respetados en el procedimiento mismo en que se dicten. cuando dichas disposiciones no ameritan recurso alguno".

La preclusión es entonces, la pérdida, extinción o consumación de una faculiad procesal determinadas por tres situaciones diferentes: a) por no haberse observado el orden preestablecido por la ley para ejercitarla; b) por haberse hecho uso de una actividad incompatible con la ejecución ce oira anterior $y$ c) por haberse ejecutado una vez válidamente dicha facultad.

La primera situación se produce cuando se deja vencer un términa sin que dentro de él se haya hecho uso de algún recurso, de algún acto procesal en sentido general, es en este aspecto que la preclusión tiene cierta analogía con la prescripción en el sentido que dejamos señalado con ia clausura del término para apelar, expresar agravios, ofrecer prueba, cuando se ha hecho uso de estas facultades procesales en el término fijado por la ley.

La segunda situación se origina cuando se realiza algún acto incormfatible con otro, verbi gratia, contestar la demānda sin deducir previamente las excepciones dilatorias a que hubiere lugar. En esta hipótesis ha preciuído el derecho de la parte a ejercitar una facultad procesal sin que la causa determinante de esta situación sea la extinción por el transcurso del tiempo.

La tercera situación se refiere al caso de terminar el proceso por sentencia o transacción o por cualquier otro medio que otorgue a la última resolución del Juez el valor de cosa juzgada, por eso se ha dicho que la cosa juzgada es la máxima preclusión, no obstante que se trata de dos instituciones distintas cuya diferencia consiste en que mientras los efectos de la preclusión se concretan única y exclusivamente al proceso, la cosa juzgada lleva sus efectos fuera de él. Quizá puede encontrarse cierta coincidencia con la llamada cosa juzgada formal, que sólo surte efectos dentro ael proceso, pero esa aparente analogía se disi $\vec{p} \alpha$ si tenemos presente que la cosa juzgada formal con el transcurso del tiempo se convierte en cosa juzgada material, tal es el caso de los procedimientos no contenciosos, cuyaresolución final queda firme si no es impugnada en el término de ley.

El concepto de preclusión tiene pues una amplitud considerable, y rio equivale a la prescripción extintiva del Derecho Civil como se ha sostenido; no siendo indispensable que exista en la legislaciones en fornua expresa como en la Ley Mejicana, basta como sucede entre nosotros. que la estructura del proceso la origine. 